\title{
Free gracilis flap for chest wall reconstruction in male patient with Poland syndrome after implant failure
}

\author{
Mario Cherubino, Francesca Maggiulli, Igor Pellegatta, Luigi Valdatta \\ Department of Biotechnology and Life Sciences (DBSV), University of Insubria, ASST sette laghi, Viale Borri 57, Varese, Italy
}

Address for correspondence: Dr. Francesca Maggiulli, Department of Biotechnology and Life Sciences (DBSV), University of Insubria, ASST sette laghi, Viale Borri 57, Varese, Italy. E-mail: francesca.maggiulli@live.it

\begin{abstract}
Poland's syndrome (PS) is a congenital monolateral deformity that may involve breast, chest wall, and upper limb with different degrees of clinical expressions. In some cases, the problem is mainly cosmetic, and the reconstruction should be performed to achieve minimal scarring and donor site morbidity. The authors describe a case report of a male patient with PS who developed a severe capsular contraction after 25 years implant reconstruction, who was treated after explantation using free gracilis flap (FGF). In this patient, only the pectoralis major muscle was missing. An FGF was performed to reconstruct the anterior axillary fold and the soft tissue defect. There was no flap loss, the patient had a clearly improved appearance of the chest wall, and the pain syndrome was solved. In this case report, we demonstrate our experience with the use of an FGF for chest wall reconstruction in male patients with PS after prosthesis explantation.
\end{abstract}

\section{KEY WORDS}

Capsular contracture; chest wall deformity; gracilis free flap; Poland's syndrome

\section{INTRODUCTION}

oland's syndrome (PS) is characterized by unilateral chest wall and upper-limb abnormalities..$^{[1,2]}$ The incidence is more in male than in female, with a ratio of about $3: 1 .^{[3]}$ The etiological hypothesis is identified in vascular origin: the unilateral hypoplasia is due to defective blood supply in subclavian arteries or their branches around the $6^{\text {th }}$ week of embryologic development. ${ }^{[4]}$ The operative reconstruction of the chest

\begin{tabular}{|l|l|}
\hline \multicolumn{2}{|c|}{ Access this article online } \\
\hline Quick Response Code: & Website: \\
\hline & www.ijps.org \\
\cline { 2 - 2 } & \\
\hline
\end{tabular}

wall is based on anatomy, degree of severity and gender. Several treatment options have been described for chest wall reconstruction in male patients, including the use of prosthesis, ${ }^{[5]}$ local or free flap such as latissimus dorsi muscle transfer, ${ }^{[6]}$ partial latissimus dorsi flap, a rectus abdominis muscle transfer, laparoscopically harvested omental flap, ${ }^{[7]}$ and free anterolateral thigh perforator flap. ${ }^{[8]}$ Reconstruction using implant or tissue expander combined with flap and autologous fat injection are also

This is an open access article distributed under the terms of the Creative Commons Attribution-NonCommercial-ShareAlike 3.0 License, which allows others to remix, tweak, and build upon the work non-commercially, as long as the author is credited and the new creations are licensed under the identical terms.

For reprints contact: reprints@medknow.com

How to cite this article: Cherubino M, Maggiulli F, Pellegatta I, Valdatta L. Free gracilis flap for chest wall reconstruction in male patient with Poland syndrome after implant failure. Indian J Plast Surg 2016;49:249-52. 
common treatment options. ${ }^{[9]}$ The purpose of this case report is to present our technique using free gracilis flap (FGF) as autologous filler in patient with PS after prosthesis explantation, to obtain a good shape with minimal scarring, and donor site morbidity.

\section{CASE REPORT}

A 47-year-old male patient presented with unilateral breast and chest wall asymmetry from the absence of the anterior axillary fold and subclavicular hollowing on the left side. The patients were examined, and clinical as well as radiological findings (RX/ TAC) were recorded [Figure 1]. Only the pectoralis major muscle was missing on the left side, and a hypoplasia and dislocation of the nipple-areolar complex was present without other anomalies. No respiratory or functional impairment due to this deformity was reported by the patient. The patient

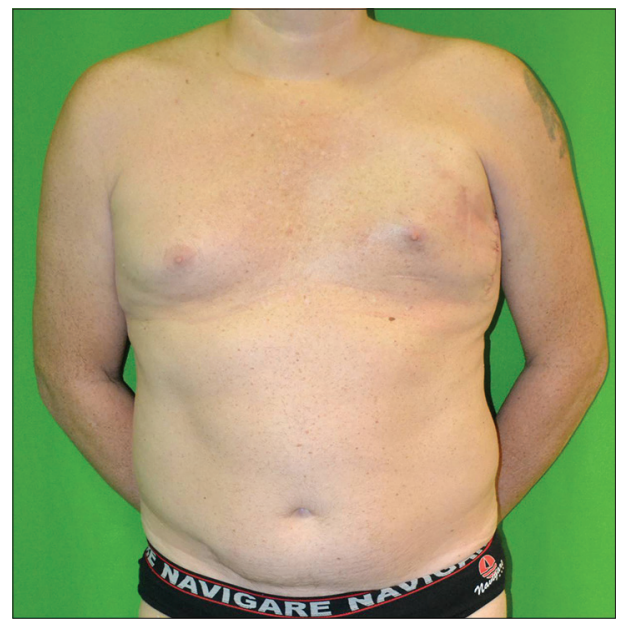

Figure 1: Preoperative picture, note the Baker 4 contracture

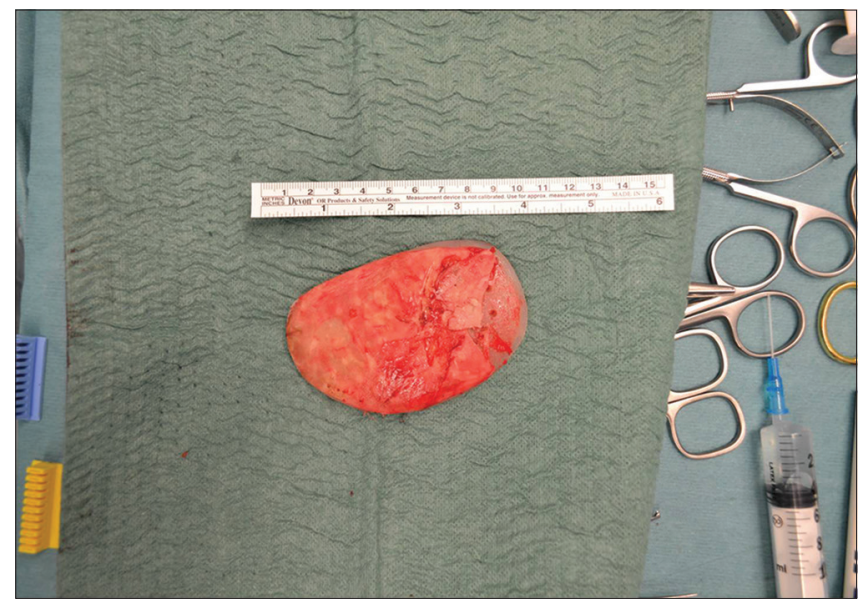

Figure 3: Implant removed underwent an aesthetic surgery 25 years before, for placement of a silicon implant, but he developed a hard capsular contracture [Figure 2]. The visual analogue scale (VAS) score was 8 . The indication for surgical treatment was not only cosmetic but also functional as the capsular contracture was painful. When the implant was removed [Figure 3] a gracilis muscle free flap was performed to improve the appearance of the chest wall. The gracilis flap was harvested from the right side. The muscle transfer procedure and the postoperative course were uneventful, and the patient left our hospital after 6 days. Physical therapy was started 4 weeks later. A clearly improved appearance was observed without any significant donor site morbidity. The gracilis flap survived. The follow-up period was 12 months. The VAS score dropped to 2 . The patient had an excellent aesthetic result. No controlateral procedure was necessary as we did not observe any significant asymmetry [Figure 4].

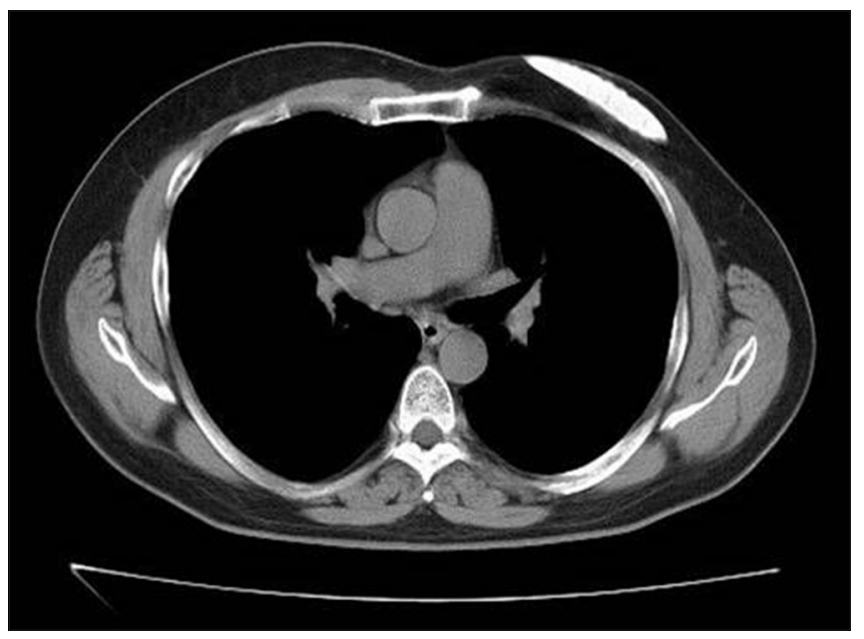

Figure 2: Computed tomography scans, chest wall with evidence of the prosthesis extrusion

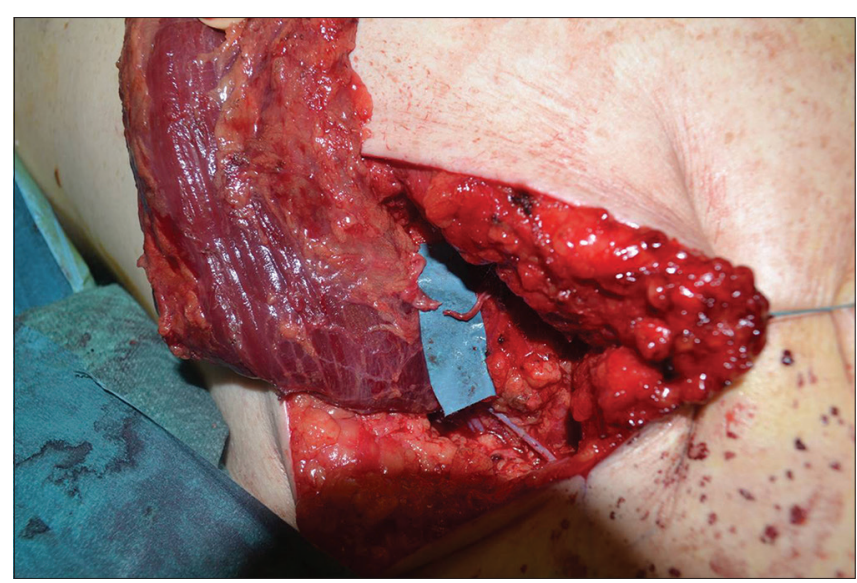

Figure 4: Neurorrhaphy gracilis motor branch with superficial intercostal nerve 


\section{DISCUSSION}

In this case report, we report our experience treating a male patient with PS using a FGF.

The key problem was mainly aesthetic, and the surgical procedure was chosen for its minimal donor site morbidity and scarring. We were able to correct successfully the aesthetic deficiency of the chest wall and the anterior axillary fold using this method. Several techniques have been used to correct deformities associated with PS, with each method featuring advantages and disadvantages. A benefit of chest wall implants (customised or not) is that, they are quickly inserted through a relatively small incision and are associated with very little scarring. Their use seems very convenient, but the limitation of implant use is that, the prosthesis does not solve the problem of the absent humoral insertion of pectoralis major, which create an anterior axillary fold. This is more evident during patient dynamism. Implant intolerance, the need of implant removal as well as postoperative displacement are further complications reported with the use of chest wall implants in male patients with PS. Chest wall reconstruction with a latissimus dorsi flap is favorable because it can reconstruct the anterior axillary fold. However, it is associated with notable donor site morbidity by leaving another scar. Even when using an endoscopically assisted approach, this method requires the transfer of an important muscle of the arm and diminishes the ipsilateral posterior axillary fold and back region. The latissimus dorsi muscle may be hypoplastic or absent in patients with this syndrome, and the use of this method may not always be reasonable. Gravvanis et al. recently reported on a patient with a moderate form of PS who underwent chest reconstruction with a free anterolateral thigh perforator flap, a method that is quickly feasible and associated with little scarring in the axillary region. To us, the distinctive long scar at the donor site speaks against this treatment option. The advantage of our method using a gracilis flap is that besides the immediate reconstruction of the chest contour and the anterior axillary fold, our method results in less scarring and insignificant donor site morbidity on a relatively unremarkable spot. A review of the literature confirmed the minimal functional and aesthetic donor-site morbidity after gracilis-flap reconstruction. ${ }^{[10]}$ Moreover, end-to-end nerve coaptation was performed between the gracilis motor branch and the superficial intercostal nerve to avoid

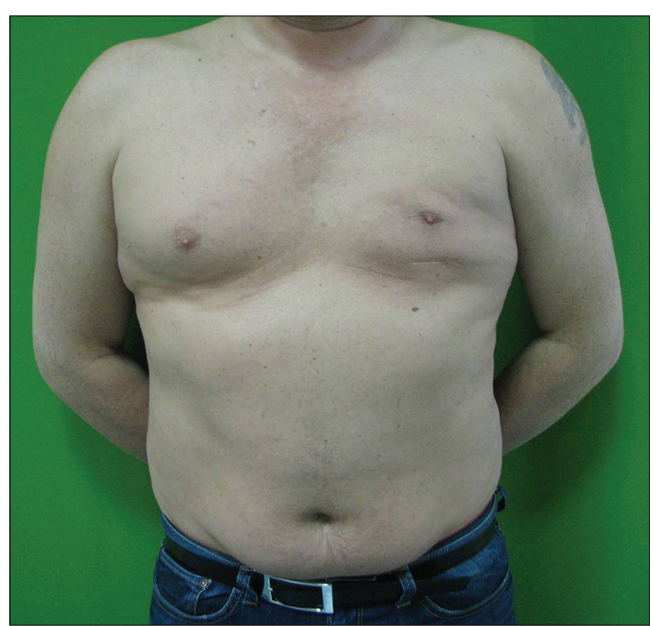

Figure 5: Postoperative picture

volume loss of muscle tissue resulting from neurogenic atrophy [Figure 5]. Although we presented only a case report and further evaluation is warranted with a larger series, we believe that a gracilis muscular flap is an optimal option for chest wall and anterior axillary fold correction in male patients with PS. This method combines minimal scarring, insignificant donor site morbidity, and an immediate excellent aesthetic result.

\section{Financial support and sponsorship}

Nil.

\section{Conflicts of interest}

There are no conflicts of interest.

\section{REFERENCES}

1. Wechselberger $G$, Hladik $M$, Reichl $H$, Ensat $F$, Edelbauer $M$, Haug $D$, et al. The transverse musculocutaneous gracilis flap for chest wall reconstruction in male patients with Poland's syndrome. Microsurgery 2013;33:282-6.

2. Poland A. Deficiency of the pectoral muscles. Guys Hosp Rep 1841;6:191-3.

3. Fokin AA, Robicsek F. Poland's syndrome revisited. Ann Thorac Surg 2002;74:2218-25.

4. Bavinck JN, Weaver DD. Subclavian artery supply disruption sequence: Hypothesis of a vascular etiology for Poland, Klippel-Feil, and Möbius anomalies. Am J Med Genet 1986;23:903-18.

5. Pereira LH, Sabatovich O, Santana KP, Picanço R, Sterodimas A. Surgical correction of Poland's syndrome in males - A purposely designed implant. J Plast Reconstr Aesthet Surg 2008;61:393-9.

6. Kelly EJ, O'Sullivan ST, Kay SP. Microneurovascular transfer of contralateral latissimus dorsi in Poland's syndrome. Br J Plast Surg 1999;52:503-4.

7. Acarturk TO, Swartz WM, Luketich J, Quinlin RF, Edington $\mathrm{H}$. Laparoscopically harvested omental flap for chest wall and intrathoracic reconstruction. Ann Plast Surg 2004;53:210-6.

8. Gravvanis A, Lo S, Shirley R. Aesthetic restoration of Poland's syndrome in a male patient using free anterolateral thigh

Indian Journal of Plastic Surgery May-August 2016 Vol 49 Issue 2 
perforator flap as autologous filler. Microsurgery 2009;29:490-4.

9. Pinsolle V, Chichery A, Grolleau JL, Chavoin JP. Autologous fat injection in Poland's syndrome. J Plast Reconstr Aesthet Surg 2008;61:784-91.
10. Papadopoulos $\mathrm{O}$, Konofaos $\mathrm{P}$, Georgiou P, Chrisostomidis C, Tsantoulas Z, Karypidis D, et al. Gracilis myocutaneous flap: Evaluation of potential risk factors and long-term donor-site morbidity. Microsurgery 2011;31:448-53. 